\title{
Differences in growth rates of the sea urchin Echinocardium cordatum as estimated by the parameter $\omega$ of the von Bertalanffy equation applied to skeletal rings
}

\author{
G. C. A. Duineveld ${ }^{1}$ and M. I. Jenness ${ }^{2}$ \\ ${ }^{1}$ Netherlands Institute for Sea Research, Postbox 59, Den Burg, Texel, The Netherlands \\ ${ }^{2}$ Davis and Elkins College, Elkins, West Virginia, USA
}

\begin{abstract}
Initial observations on the echinoderm Echinocardium cordatum collected in the southern North Sea indicated that the maximum attainable size for this species differed in the different substrate sampled. This suggested either a difference in longevity or in growth rates. A method of aging $E$. cordatum is presented which also allows incremental annual growth of an individual to be calculated. The parameter $\omega$, derived from the parameters $k$ and $L \infty$ of the von Bertalanffy growth model, was used to compare the growth rate of $E$, cordatum at different sites. Analysis of approximately 2,000 specimens collected from different points along a north-south transect showed an increasing rate of growth from north to south. Maximum size of the organisms also increased in the same direction. No differences in longevity were observed. The causative factors are still speculative at this time. However, a number of physical parameters which form gradients along the transect, provide several interesting possibilities for future investigations. The most promising of these is bottom temperature. The highest rate of growth for this organism occurs in sediments containing the lowest amounts of organic matter and biomass. This poses interesting questions regarding its food and feeding habits.
\end{abstract}

\section{INTRODUCTION}

Although Moore (1936) reported that Echinocardium cordatum is essentially a littoral species, more recent studies have shown that the greater portion of the population, at least in the North Sea, is found well offshore, reaching a maximum density at depths of $40 \mathrm{~m}$ (Ursin, 1960). The species is ubiquitous throughout the North Sea, but high variations in test lengths and density exist among the various stocks (Ursin, 1960; Buchanan, 1966; van Noort et al., 1979). In the southern North Sea, the gradual decrease in tidal current velocity from south to north, coupled with increasing depth, has caused a gradient to occur in the median grain size of the recently deposited bottom sediment (Creutzberg and Postma, 1979). Since 1975, this region has been intensively studied in terms of physical parameters, primary productivity, and the ecology of various benthic species (Fransz, 1976, 1977; Gieskes and Kraay, 1977; Creutzberg and Postma, 1979; Creutzberg et al., 1984). Preliminary sampling of $E$. cordatum along this gradient revealed noticeable differences in observed maximum test lengths. These appeared to correspond to differences in sediment types. Ursin (1960) and Buchanan (1966) have reported similar findings, but were unable to determine whether the differences were due to differential growth rates or to differential longevity. The development of a technique to age accurately echinoids by Jensen (1969) was modified by the present authors to determine both age and rates of growth of $E$. cordatum. This made it possible to compare the different stocks in terms of these parameters.

\section{SITE DESCRIPTION}

The area under investigation lies north-east of the Dutch coast from Latitude $53^{\circ} \mathrm{N}$ to $54^{\circ} 30^{\prime} \mathrm{N}$ and from Longitude $4^{\circ} \mathrm{E}$ to $5^{\circ} \mathrm{E}$. From south to north there is an increasing depth (20 to $50 \mathrm{~m}$ ) and a decreasing velocity in tidal current (1.8 to 0.7 knots) (Fig. 1). These factors 
are responsible for the observed transition of sediment. from coarse to fine (median grain sizes from 300 to $100 \mu \mathrm{m}$ ) (Creutzberg et al., 1984).

At Latitude $53^{\circ} 35^{\prime}$ there is a marked discontinuity separating the sandy sediments in the south from the rnuddy sediments in the north. This boundary corres- levels (25 $\mathrm{g} \mathrm{AFDW}^{-2}$ ) and high organic carbon content $(4 \%)$ in the sediment which extends approximately $15 \mathrm{~km}$ to the north of this boundary. Creutzberg (1983) has shown that chlorophyll a concentration shows a maximum during most periods of the year in the water column above this nutrient-enriched zone,

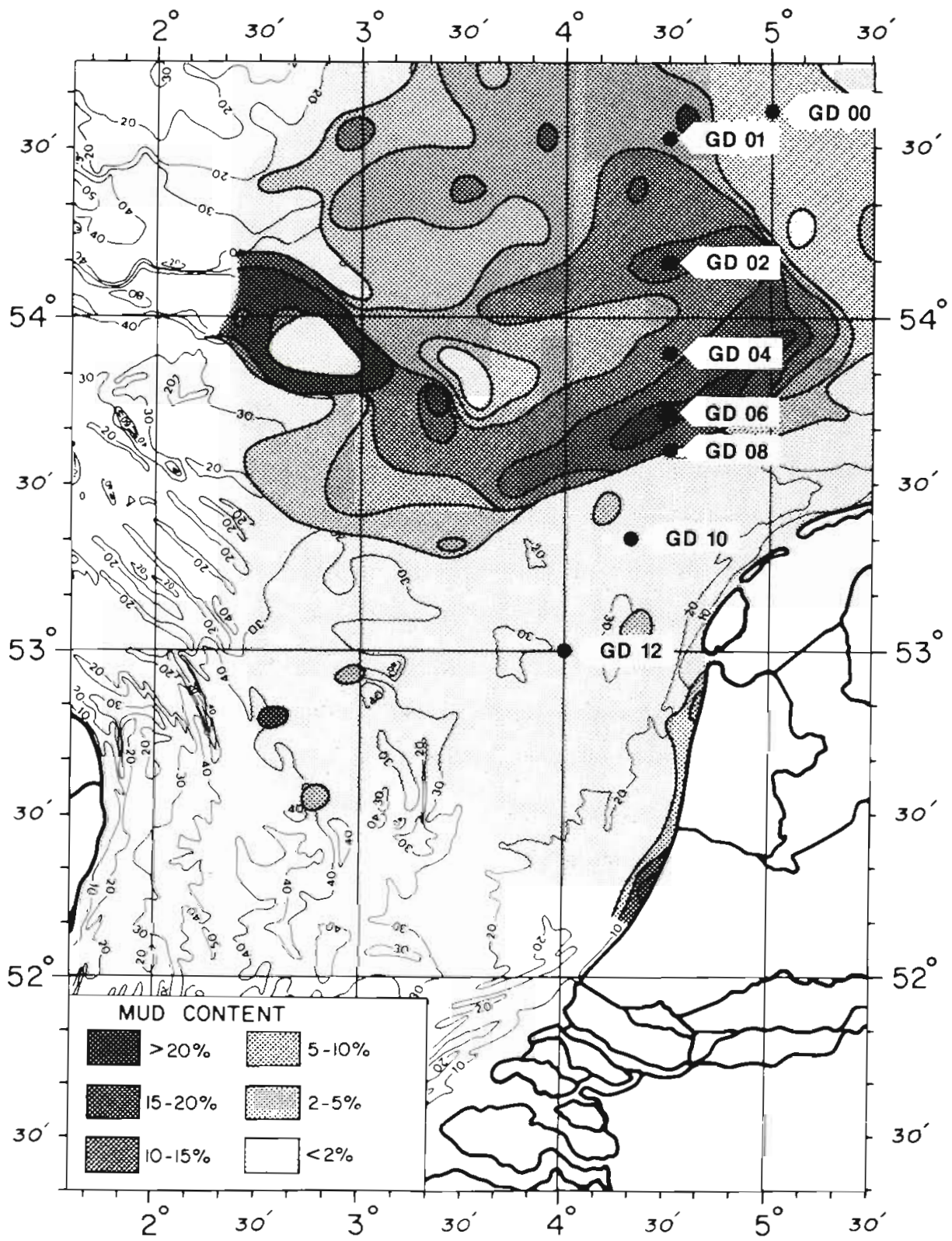

Fig. 1. Location of sampling sites in relation to distribution of sediment mud content ( $\%$ particles $<50 \mu \pi n\}$

ponds closely with both the $30 \mathrm{~m}$ isobath and the line delimiting a maximum tidal velocity of 0.9 knots. The velocity of 0.9 knots has been shown to be critical in the process of sedimentation (Creutzberg and Postma, 1979). At velocities below this level, sedimentation of even the finest particles occurs, whereas at velocities above this level, fine particles will remain in suspension. This results in a zone with high benthic biomass suggesting an increased level of productivity. In the summer, a tidally induced front more or less coincides with this enriched area with stratification occurring to the north and turbulence to the south. Since this zone of higher chlorophyll a levels has also been shown to be independent of the tidally induced front, the presumably higher production is most likely a direct result of the higher fertility of the underlying bottom sedi- 
ments. The total macrobenthic biomass ranges from a value of about $4 \mathrm{~g} \mathrm{AFDW} \mathrm{m}^{-2}$ in the southern sandy areas to a value of about $11 \mathrm{~g} \mathrm{AFDW} \mathrm{m}^{-2}$ in the northern muddy sites. Peak biomass values of $25 \mathrm{~g}$ AFDW $\mathrm{m}^{-2}$ are found in the enriched zone. Echinocardium cordatum is a primary source of biomass in the sandy sites $(50 \%)$ whereas its biomass in the muddy sites is only about $5 \%$.

\section{METHODS}

Data collection. Sampling sites were established along a transect running from north to south through the study area (Fig. 1). These sites were placed at narrow intervals over the boundary zone and enriched area and at wider intervals over the more uniform areas to the north and south. Samples were taken at periodic intervals from Feb 1982 through Nov 1983. The large numbers of organisms needed for growth measurements were collected with either a van Veen grab or a $5.5 \mathrm{~m}$ beam trawl. The latter was equipped with heavy tickler chains to maximize the depth of penetration into the substrate. Samples for biomass measurements were made with a Reineck box sampler, capable of sampling $0.06 \mathrm{~m}^{2}$ surface to a depth of 15 to $40 \mathrm{~cm}$. Estimates of density were also possible with this sampling method; however, the limited number of samples taken per site per sampling period (18 samples) reduces the reliability of these estimates. Also, Echinocardium cordatum is known to live up to $20 \mathrm{~cm}$ deep in sandy sediments. Since the sampling devices described above are less effective in penetrating sandy sediments than muddy sediments, densities will be underestimated in these sandy sites.

Age and rate of growth were determined by counting and measuring the growth rings on the ventral 'foot' plate. All plates were found to form rings, but the foot plate was used for 2 reasons (1) because of it's large size relative to the other plates; (2) because it's asymmetric growth pattern provided an initial point of growth to which all measurements could be compared (Fig. 2). The plates were prepared using a modified version of the method described by Jensen (1969). After measuring the test length of a specimen, the foot plate was removed using a hobby electric saw. The plate was cleaned with alcohol and then burned in a bed of glass beads on an electric hot plate for approximately 2 to $3 \mathrm{~min}$, or until it turned a light tan color. The plate was then put into a shallow dish containing xylene and examined under a dissecting microscope. The length of each ring was easily determined with an ocular micrometer to the nearest $0.1 \mathrm{~mm}$.

Jensen (1969) concluded that the dark band of each ring was formed during the summer (growth period) and that the light band was the winter ring. Careful examination of specimens of all ages has convinced us that the opposite is the case. Of the specimens collected with the van Veen grab in September or October, the smallest ( 6 to $12 \mathrm{~mm}$ ) were assumed to have certainly completed one summer's growth. Likewise, since these specimens were undoubtedly the result of the current year's spatfall, they almost certainly had not yet overwintered. Inspection of these small specimens revealed uniformly light-colored ventral plates without any evidence of bands (Fig. 2). Organisms collected in the spring and early summer, in the size range of 10 to $15 \mathrm{~mm}$, showed a different pattern; the original central band now appears dark and is surrounded by a light band. After the second winter, this light band becomes darker and is delineated by an even darker boundary (Fig. 2). Continued growth produces alternating light and dark bands (Fig. 3). All measurements and calculations are based on the premise that each full year's growth is terminated at the distal margin of each dark (winter) band.

Data analysis. From these observations, a linear regression was calculated comparing plate lengths (PL) in $\mathrm{mm}$ with test lengths (TL) in $\mathrm{mm}$ :

$(\mathrm{TL}=1.92 \times \mathrm{PL}+1.90 \mathrm{~mm}): \mathrm{r}^{2}=0.976, \mathrm{~N}=1,963$

The high coefficient of correlation along with the high number of observations for this regression indicates a very reliable correlation between these 2 variables. The intercept value of $1.90 \mathrm{~mm}$ is interpreted as the length of the organism at the time of settling and agrees very well with observed values for recently settled larvae. At this point, plate growth has not begun, thus plate length would equal zero.

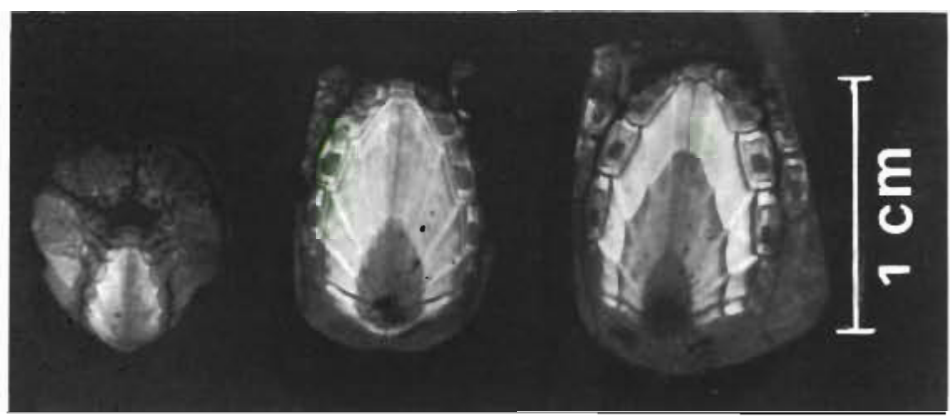

Fig. 2. Echinocardium cordatum. Ventral plates of 3 different specimens. The plate on the left is from a specimen which has not yet completed the first year's growth. The center plate has 1 complete ring, surrounded by an incomplete ring from the current year's growth. The plate on the right has 2 complete rings and 1 incomplete ring. Only complete rings were used in calculating growth 


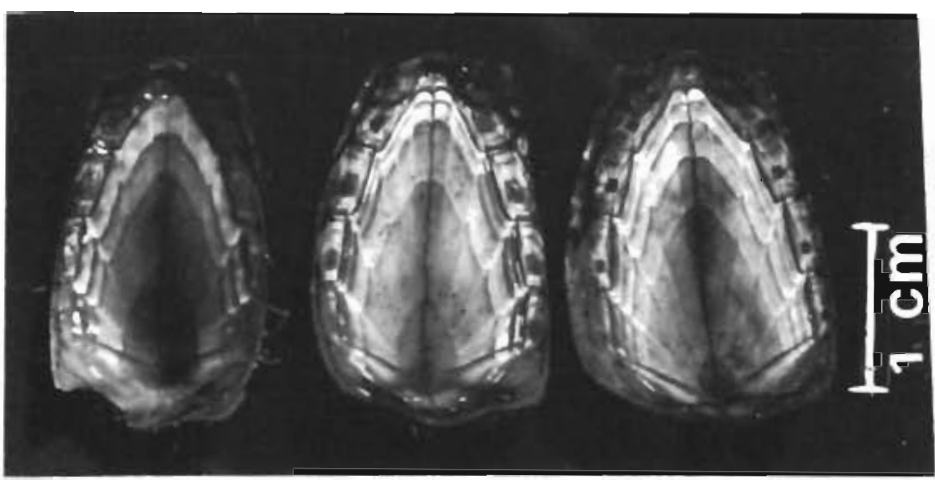

Fig. 3. Echinocardium cordatum. Ventral plate showing 4 complete rings and 1 incomplete ring. Note the marked differences in the length of the first ring

Using this Equation (1), the test length corresponding to each ring length of each organism was calculated. For each site, length (y) was plotted against age $(\mathrm{x})$ and growth was modeled by fitting various growth curves to the plotted data. One or more of 3 models consistently gave a good fit. The linear model $(\mathrm{y}=\mathrm{ax}$ + b) frequently gave the best fit when only the early growth phases were analyzed. It is possible that linear growth in fact does occur prior to the onset of sexual maturity, which probably occurs around the third year. The logarithmic model $(y=a+b \log x)$ also frequently gave a good fit, however, since this model is not asymptotic, it was also rejected. The third model which consistantly gave a good fit was the von Bertalanffy growth model $\left(\mathrm{L}_{\mathrm{t}}=\mathrm{L}_{\infty}\left(1-\mathrm{e}^{-\mathrm{k}\left(\mathrm{t}-\mathrm{t}_{0}\right)}\right)\right.$. In this model, the parameter $\mathrm{k}$ is a growth constant (not a growth rate), Lo estimates the asymptotic maximum size, and $t_{o}$ is the extrapolated time when length is equal to zero. Unfortunately, $\mathrm{k}$ and $\mathrm{L} \infty \max$ have been shown to be negatively correlated, which creates difficulty in interpreting these values, especially when comparing different populations (Knight, 1968). For this reason, the von Bertalanffy model was reparameterized, as suggested by Gallucci and Quinn (1979) and tests of comparison were performed on the new, single parameter $\omega$ where $\omega=\mathrm{kL} \infty$. This parameter estimates the instantaneous growth in the neighbourhood of $L\left(t_{0}\right)=0$. All individuals with 2 rings or less were eliminated from the analysis. Simulation experiments by Vaughan and Kanciruk (1982) revealed that inclusion of data contributing only to the ascending limb of the von Bartalanffy equation seriously affected the accuracy and precision of the parameter estimates. This results from insufficient curvature in the data for estimating $L \infty$. Our analysis confirmed these observations when we included one and 2 -yr old organisms in the sample.

Traditionally, linear methods have been used on transformed data to estimate the parameters of the von Bertalanffy model (Walford, 1946; Tomlinson and Abramson, 1961; Allen, 1966; Bayley, 1977). These linear methods have been shown to be less reliable in estimating the von Bertalanffy parameters than can be obtained by using a non-linear method (Gallucci and Quinn, 1979; Vaughan and Kanciruk, 1982). Nonlinear methods also allow for the estimation of error for each parameter, a necessary condition for tests of comparison.

For these reasons, the parameter estimates for each site were determined using the iterative Gause-Newton non-linear procedure. The variance of the estimate $\omega$ was found by using the approximation of the variance of a product (Goodman, 1960). The t-statistic was used to test for significant differences in $\omega$ between sites as suggested by Allen (1966) and Gallucci and Quinn (1979).

Since the $L \infty$ calculated from the von Bertalanffy equation is confounded with $\mathrm{k}$, it is not a reliable value to use to compare maximum attainable size between sites. Instead, comparisons were made using the mean size of the largest organisms collected from each site. The assumption was made that organisms which had reached their sixth year approach asymptotic size (Fig. 4). For each site, the measured test lengths of these organisms were summed and the mean calculated. These means were tested for significant differences using the t-statistic.

\section{RESULTS}

The values obtained for the parameters $L \infty, k$, and $\omega$ at the several sites are summarized in Tables 1 and 2 . While no pattern is discernable for the values of either $\mathrm{k}$ or $\mathrm{L} \infty$, a very clear trend occurs for the parameter $\omega$. In general, the values for $\omega$ are lowest in the north and highest in the south. Additionally, 3 distinct clumps of values can be identified. The values for $\omega$ in the southern sandy sites (GD10, GD12) are very similar to each other, but significantly different from all other sites. The same is true for the northern muddy sites (GD00, GD01, GD02, GD04), with the exception of site GD02. Although the estimate of $\omega$ for site GD02 is significantly different from the other northern muddy sites (Table 2), the levels of significance for the most part are not as high as between GD02 and the non-muddy 
Table 1. Results of estimated parameters for von Bertalanffy growth model for each sample site

\begin{tabular}{l|c|c|c|r}
\hline Site & $\omega$ & $K$ & $L_{\infty}$ & \multicolumn{1}{|c}{$N$} \\
\hline GD 00 & 12.793 & 0.394 & 32.47 & 28 \\
GD 01 & 13.345 & 0.393 & 33.96 & 240 \\
GD 02 & 14.356 & 0.388 & 36.99 & 156 \\
GD 04 & 12.722 & 0.295 & 43.30 & 24 \\
GD 06 & 17.315 & 0.480 & 36.07 & 382 \\
GD 08 & 17.139 & 0.442 & 38.78 & 977 \\
GD 10 & 22.503 & 0.517 & 43.53 & 71 \\
GD 12 & 22.198 & 0.485 & 45.77 & 85 \\
\hline
\end{tabular}

Table 2. Significance levels for t-test comparisons of growthrate parameter $\omega$

\begin{tabular}{|c|c|c|c|c|c|c|c|}
\hline GD 01 & " & & & & & & \\
\hline GD 02 & $*$ & " & & & & & \\
\hline GD 04 & & & $\star$ & & & & \\
\hline GD 06 & $\because$ & ** & $*$ & $\cdots$ & & & \\
\hline GD 08 & $\cdots$ & "* & $* *$ & $*$ & * & & \\
\hline GD 10 & $\because$ & $* *$ & $* *$ & $*$ & ** & $*$ & \\
\hline GD 12 & 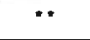 & $" n$ & $\because$ & $*$ & $" *$ & ** & * \\
\hline Site & GD 00 & GD 01 & GD 02 & GD 04 & GD 06 & GD 08 & GD 10 \\
\hline
\end{tabular}

- 90th percentile; $\cdots 99$ th percentile

sites. The values of $\omega$ for sites GD06 and GD08 are similar to each other and intermediate between the values found in the sandy and the muddy sites. They are also significantly different from the values for either of these areas.

The robustness of the parameter $\omega$ is well illustrated by the results for GD04. This sample is composed exclusively of young specimens which have not yet reached maximum size. These conditions tend to underestimate $\mathbf{k}$ and overestimate $\mathrm{L} \infty$ as predicted by the simulation experiments of Vaughen and Kanciruk (1982). The estimated value for the parameter $\omega$ is somewhat lower than one would expect from the apparent north-south trend (Table 2), but is still very much in line with the $\omega$ values found at the other muddy sites.

The data for mean maximum test length at each site are summarized in Tables 3 and 4. Maximum test length is significantly greater at the sandy sites (GD10, GD12) than at either the intermediate sites (GD06, GD08) or at the muddy sites (GD00, GD01, GD02, GD04). Mean test lengths at sites GD06 and GD08 are intermediate in value between values found at the sandy sites and at the northern muddy sites. They are significantly less than the values at the sandy sites and appear to be greater than the values at the muddy sites. These latter differences, however, are either insignificant or only marginally significant.
Table 3. Calculated means and standard deviations for maximum attained test lengths of specimens 6 yr and older

\begin{tabular}{l|c|c|c}
\hline Site & Mean & S.D. & N \\
\hline GD 00 & 36.75 & 0.35 & 2 \\
GD 01 & 35.83 & 2.10 & 21 \\
GD 02 & 35.54 & 3.92 & 9 \\
GD 04 & - & - & - \\
GD 06 & 37.66 & 2.72 & 33 \\
GD 08 & 37.73 & 1.89 & 22 \\
GD 10 & 43.73 & 1.89 & 8 \\
GD 12 & 45.73 & 3.84 & 8 \\
\hline
\end{tabular}

Table 4. Significance levels for t-test comparisons of maximum attained test lengths

\begin{tabular}{|c|c|c|c|c|c|c|}
\hline GD 01 & & & & & & \\
\hline \multicolumn{7}{|l|}{ GD 02} \\
\hline GD 06 & & $*$ & * & & & \\
\hline GD 08 & & $\cdots$ & * & & & \\
\hline GD 10 & 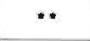 & $*$ & $* *$ & ** & ** & \\
\hline GD 12 & $*$ & $*$ & ** & $*$ & $*$ & \\
\hline Site & GD 00 & GD 01 & GD 02 & GD 06 & GD 08 & GD 10 \\
\hline
\end{tabular}

-90th percentile; $\cdots$ 99th percentile

Accurate estimates of density were not made, but preliminary observations indicate that the density is clearly higher in the boundary area (GD06, GD08).

\section{DISCUSSION}

These results clearly show that the initial rate of growth of Echinocardium cordatum, as defined by the parameter $\omega$, is highest in the southern sites and decreases significantly in the northern sections of the study area. Maximum attainable test length follows the same pattern, with the largest specimens being found in the south and the smallest in the north. Since the trend observed for maximum length corresponds closely with the trend observed for growth rates, it is probable that maximum length is determined by growth rate. Greater length could also have been achieved by increased longevity. However, no distinctive differences in longevity were observed among the various sites (Fig. 4).

Our results do not support the contention of Buchanan (1966) that mud content of the sediment is a direct causative factor in determining growth rates of Echinocardium cordatum. If this were true, then lowest growth rate would have occurred at those sites with the highest mud content (GD06 and GD08). In fact, sea urchins at these sites have significantly higher growth rates than those at the less muddy northern sites 


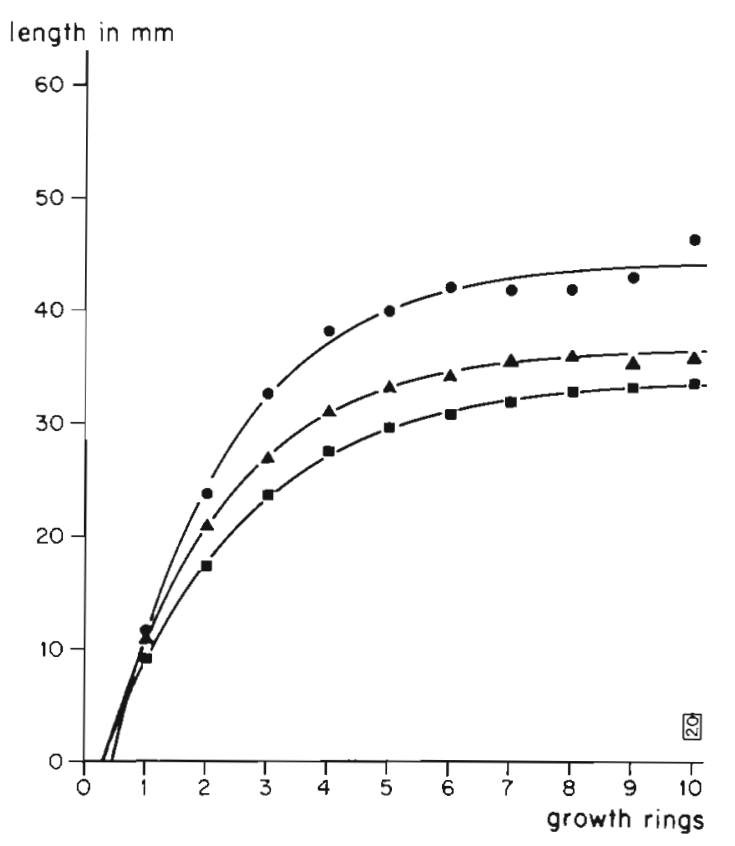

Fig. 4. Von Bertalanffy growth curves for: $\bullet=$ southern sandy sites (GD10, GD12); $\Delta=$ intermediate sites (GD06, GD08) - = northern sites (GD00, GD01, GD02, GD04)

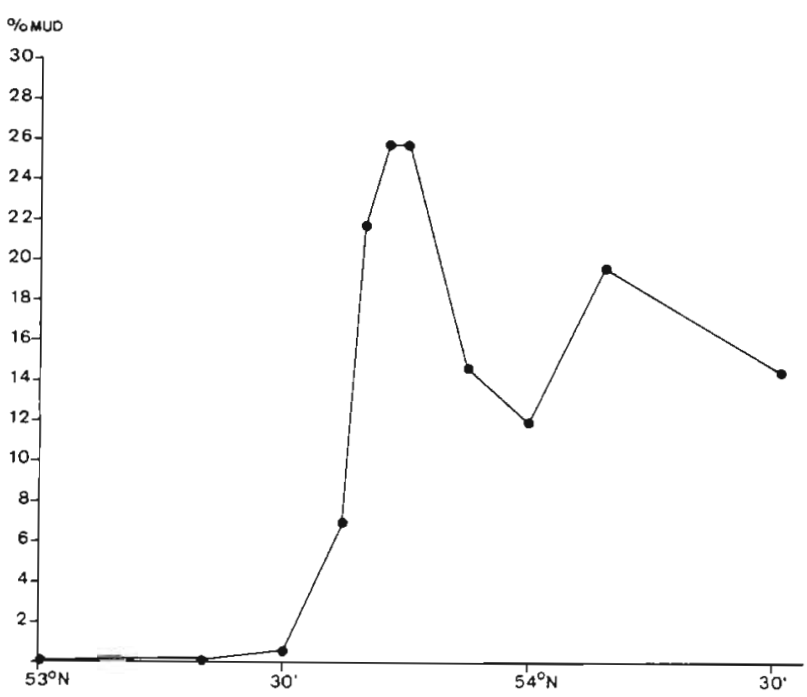

Fig. 5. Change in mud content (\% particles $<50 \mu \mathrm{m})$ with latitude along sample transect

(Fig. 5). For the same reason, it is unlikely that growth rates are simply correlated with percent organic matter, biomass, or primary productivity. Preliminary data collected in the same area by de Wilde (pers. comm.) suggest that the percent saturation of oxygen of the bottom water in summer is also related to the percent mud in the sediment. Thus, many of the possible parameters affecting growth rates of $E$. cordatum in the southern North Sea can probably be eliminated as single causative factors. The possibility of interactions between 2 or more of these parameters could, however, produce the observed results.
Although rate of growth can be influenced by many environmental parameters, temperature could certainly be ranked as one of the more important. The bottom temperatures at various points along our transect show a continuous gradient from south to north, at least during summer (Fig. 6). The annual summer stratification of the water masses over the northern sites causes lower bottom temperatures in summer which in turn could effectively explain the lower growth rates at these sites. This, of course, assumes that increased growth rates are positively correlated with increased temperatures, an as yet untested assumption for this species. Undoubtedly, other single parameters may also have a continuous gradient. How-

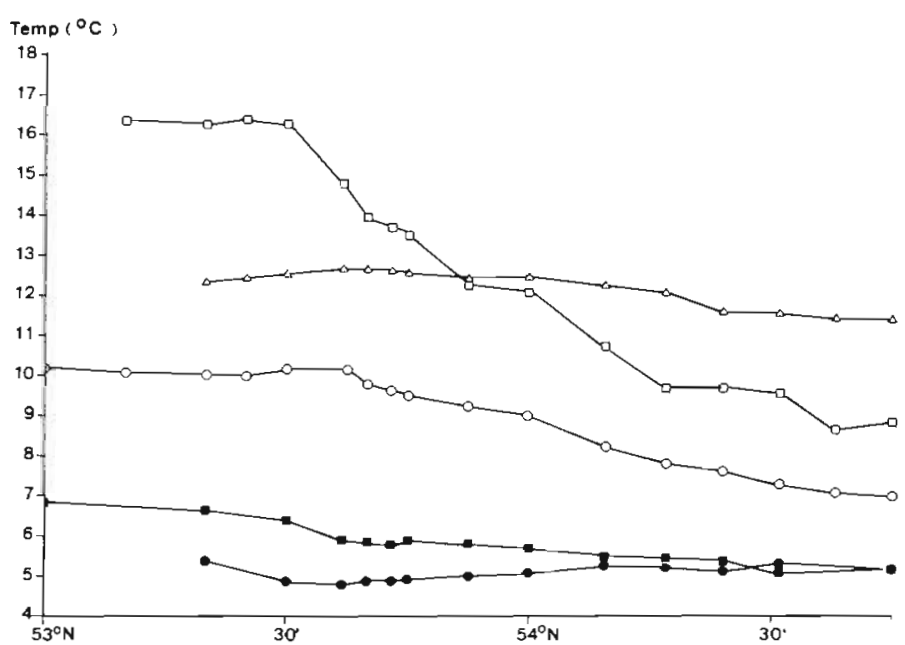

Fig. 6. Bottom temperature profile for various months during 1983: $\bullet=$ Feb; $\square=$ Apr $_{i} O=$ May; $\square=J_{u l} \boldsymbol{\Lambda}=$ Nov (after data from Creutzberg, 1983)

ever, it is reasonable to expect that several of these parameters, including temperature, may be interrelated. Appeldoorn (1982) used the method of Principal Components Analysis to allocate the degree of influence of various environmental parameters contributing to observed $\omega$ values for the bivalve Mya arenaria in different sites. Although he found highly significant correlations, causality was still speculative. Hence, if $\omega$ is correlated to one parameter, it may well be correlated to several others, in which case causality would be nearly impossible to determine. It will perhaps be more profitable, albeit more time-consuming, to determine experimentally the effects of each single parameter independently on $\omega$.

In addition to physical parameters, various biological parameters can affect growth rates. For example, differential growth rates could certainly be a consequence of genetic isolation of the sampled populations. However, the physical conditions of the area sampled (relatively small area, seasonally high mixing rate of the waters, absence of any physical boundaries), cou- 
pled with the continuous distribution of this species over the entire area, would tend to suggest that such isolation does not occur.

Reduced growth rates could also be observed if food were limiting, either in absolute terms, or as a consequence of competition. It is not altogether clear, however, just what the primary food source of this species consists of or even what feeding mechanism or mechanisms it employs. The feeding pattern of this species was investigated by several authors, notably Uexküll (1907), Gandolfi Hornyold (1909, 1910), Gislen (1924), Yonge $(1928,1949)$ and Buchanan (1966). Uexküll proposed that these urchins feed by shoveling bottom deposits into the mouth while moving over the bottom. Gislen (1924) and Gandolfi Hornyold (1909. 1910) observed that urchins burrow into the substrate and maintain contact with the surface via a mucuslined canal. Although Uexküll had also observed this canal, he attributed its function solely to respiration. Gislen noted, that in addition to respiratory function, this tube also serves a feeding function. Extensile tube feet with rosette 'hands' emerge from this tube, collect food particles from the surface, then withdraw into the tube. Buchanan (1966) observed that only in sandy sediments do urchins develop the respiratory canal and feed as described by Gandolfi Hornyold and Gislen. In muddier sediments, Buchanan found that they remain near the surface, and presumably feed by some other method.

These studies would seem to indicate that this species is, at least, a surface deposit feeder. However, Creutzberg et al. (1984) have reported that deposition of organic matter is very low, if not non-existent, in the southern sandy sites, and that the biomass and the percent organic matter of the sediment is also very low. Therefore, it becomes very difficult to explain, at least in terms of food availability, why Echinocardium cordatum has the highest rate of growth in this area. One possibility is that higher levels of intraspecific competition exist in the richer sites, causing the reduced growth rates observed at these sites. However, more reliable data on population densities of this species, and on the effects of high density on growth rates, are required before this can be determined. Interspecific competition could also lead to food limitation at the richer sites. However, the effects of this parameter requires precise knowledge of the food source of this species, as well as the degree to which it must compete with other species for this food source. It is also possible that this species is capable of exploiting food resources other than surface-deposited organic matter. Such 'opportunistic feeding' has been documented for numerous species by several authors. Examples have been reported for various polychaetes (Krüger, 1959; Goerke, 1971; Fauchald and Jumars, 1979), echinoderms (Ockelmann and Muus, 1978; Seilecher, 1979), and molluscs (Hughs, 1969; Reid and Reid, 1969; Hylleberg and Gallucci, 1975). A third possibility is that E. cordatum is capable of utilizing transitory deposition of organic matter. Even though net erosion exceeds net deposition in the southern sandy sites, due to higher maximum tidal current velocities, this process could well be reversed temporarily during periods of slack tide. Surface-deposit feeders would thus be provided with a fresh food supply once or twice each day.

The pattern which seems to be emerging from these observations is one where temperature, perhaps in conjunction with other physical parameters, is the primary determinant of growth rate in Echinocardium cordatum. This urchin, however, lives under wide ranging conditions, suggesting that it is capable of utilizing a variety of feeding mechanisms to exploit a variety of food sources. Studies presently underway by the authors are designed to attempt to determine these capabilities.

Acknowledgements. The authors thank the crew of the R. V. 'Aurelia' for help in taking samples; Mr. R. Dapper for assistance in the computer analysis of our data; Mr. H. Hobbelink for assistance in the preparation of the graphs; and Drs. F. Creutzberg, B. Kuipers, and M. Fonds for critical reading of our manuscript.

\section{LITERATURE CITED}

Allen, R. K. (1966). A method of fitting growth curves of the von Bertalanffy type to observed data. J. Fish. Res. Bd Can. 23 (2): 163-179

Appeldoorn, R. S. (1983). Variation in the growth of Mya arenaria and its relationship to the environment as analyzed through principal component analysis and the $\omega$ parameter of the von Bertalanffy equation. Fish. Bull. U.S. 81 (1): 75-84

Bayley, P. B. (1977). A method for finding the limits of application of the von Bertalanffy growth model and statistical estimates of the parameters. J. Fish. Res. Bd Can. 34: 1079-1084

Buchanan, J. B. (1966). The biology of Echinocardium cordatum (Echinodermata: Spatangoidea) from different habitats. J. mar. biol. Ass. U.K. 20; 655-671

Creutzberg, F., Postma, H. (1979). An experimental approach to the distribution of mud in the southern North Sea. Neth. J. Sea Res. 13 (1): 99-116

Creutzberg, F. (1983). Biological activity in an area with a tidally induced front. ICES, Biological Oceanography Committee, C.M. 1983/L: 4: 1-13

Creutzberg, F., Wapenaar, P., Duineveld, G., Lopez Lopez, N. (1984). Distribution and density of the benthic fauna in the southern North Sea in relation to bottom characteristics and hydrographic conditions. Rapp. P.-v. Réun. Cons. int. Explor. Mer 183: 101-110

Fauchald, K., Jumars, P. A. (1979). The diet of worms a study of polychaete feeding guilds. Oceanogr. mar. Biol. A. Rev. 17: 193-284 
Fransz, H. G. (1976). The spring development of calanoid copepod populations in the Dutch coastal waters as related to primary production. In: Persoone, G., Jaspers, E. (ed.) 10th European Marine Biology Symposium, Ostend, Belgium, Vol, 2. Universa Press, Wetteren, p. 247-269

Fransz, H. G. (1977). Produktiviteit van zoöplankton in de zuidelijke bocht van de Nordzee. Vakbl. Biol. 57 (17): 288-291

Gallucci, V. F, Quinn II, T. J. (1979). Reparameterizing, fitting and testing a simple growth model. Trans. Am. Fish. Soc. 108: 14-25

Gandolfi Hornyold, A. (1909). Uber die Nahrungsaufnahme der Spatangiden. Biol. Centralbl. 29: 759

Gandolfi Hornyold, A. (1910). Beiträge zur Anatomie und Biologie der Spatangiden. Fribourg Mem. Soc. Sci. Nat., 1: 25

Gieskes, W. W. C., Kraay, G. W. (1977). Primary production and consumption of organic matter in the southern North Sea during the spring bloom of 1975 . Neth. J. Sea Res. 11 (2): $146-167$

Gislen, T. (1924). Echinoderm studies. Zool. Bidr. Upps. 9: $1-316$

Goerke, H. (1971). Die Ennährungsweise der Nereis-Arten (Polychaete, Nereidae) der Deutschen Küsten. Veröff. Inst. Meeresforsch. Bremerh. 13: 1-50

Goodman, L. (1960). On the exact variance of products. J. Am Stat. Ass. 55: 708-713

Jensen, M. (1969). Age determination of echinoids. Sarsia 37 : $41-44$

Hughes, R. N. (1969). A study of feeding in Scrobicularia plana. J. mar. biol. Ass. U.K. 49: 805-823

Hylleberg, J., Gallucci, V. F. (1975). Selectivity in feeding by the deposit feeding bivalve Macoma nasuta, Mar. Biol. 32: $167-178$

Knight, W. (1968). Asymptotic growth: an example of non- sense disguised as mathematics. J. Fish. Res. Bd Can. 25 (6): 1303-1307

Krüger, F. (1959). Zur Ernährungsphysiologie von Arenicola marina. Zool. Anz. 22 (Suppl.): 115-120

Moore, H. B. (1936). The biology of Echinocardium cordatum. J. mar. biol. Ass. U.K. 20: 655-671

Noort, G. J. van (ed.) (1979-1983). 'Aurelia'-cruise reports on the benthic fauna of the southern North Sea. Report 1-7. Interne Verslagen Nederlands Instituut voor Onderzoek der Zee, Texel, 1979 (5-8), 1981 (1), 1982 (7), 1983 (3)

Ockelman, K. W. Muus, K. (1978). The biology, ecology and behaviour of the bivalve Mysella bidentata (Montagu). Ophelia 17: 1-93

Reid, R. G. B., Reid, A. (1969). Feeding processes of members of the genus Macoma (Mollusca: Bivalvia). Can. J. Zool. 47: $649-657$

Seilacher, A. (1979). Constructional morphology of sand dollars. Paleobiology 5: 191-221

Tomlinson, P., Abramson, N. J. (1961). Fitting a von Bertalanffy curve by least squares. Calif. Dept. Fish and Game, Fish. Bull. 116

Uexküll, J, von (1907). Studien über die Tonus IV. Die Herzigel. Zeit. f. Biol. 49: 307

Ursin, E. (1960). A quantitative investigation of the echinoderm fauna of the central North Sea. Meddr Danm. Fisk.-og Hav., N.S. 2: 1-204

Vaughan, D. S., Kanciruk, P. (1982). An empirical comparison of estimation procedures for the von Bertalanffy growth equation. J. Cons. int. Explor. Mer 40: 211-219

Walford, L. A. (1946). A new graphic method of describing the growth of animals. Biol. Bull. mar. biol. lab., Woods Hole 90: $141-147$

Yonge, C. M. (1928). Feeding mechanisms in the invertebrates. Biol. Rev. 3: 21-76

Yonge, C. M. (1949). The sea shore. Collins, London

This paper was submitted to the editor; it was accepted for printing on May 12, 1984 